\title{
GERBANG TRANSIT TAMAN TEBET
}

\author{
Indra Aristyanto ${ }^{1)}$, Timmy Setiawan ${ }^{2)}$ \\ 1)Program Studi S1 Arsitektur, Fakultas Teknik, Universitas Tarumanagara, indraaristyanto@gmail.com \\ 2) Program Studi S1 Arsitektur, Fakultas Teknik, Universitas Tarumanagara, timmy@unitricipta.com
}

\begin{abstract}
Abstrak
Kehidupan masyarakat Jakarta yang sangat dinamis dalam rutinitasnya kadang membuat mereka lupa akan pentingnya bersosialisasi dan beristirahat sejenak. Kebutuhan akan ruang ketiga, selain rumah dan tempat kerja, dapat menjadi solusi untuk memberikan ruang yang mampu membuat masyarakat melupakan kegiatan dan melepas penat dari rutinitasnya agar memiliki kualitas hidup yang lebih baik. Kawasan Tebet sebagai salah satu kawasan permukiman yang padat di Jakarta tentu membutuhkan ruang ketiga ini agar masyarakatnya dapat memiliki kualitas hidup yang lebih baik. Keberadaan transportasi publik yang beragam di kawasan ini seperti kereta listrik, bus Transjakarta serta LRT yang masih dalam tahap pembangunan membuat alur pergerakan masyarakat yang menjadi pengguna menjadi sangat dinamis. Ruang antara rumah dan titik-titik transportasi tersebut diperlukan sebagai ruang ketiga yang menjadi titik transit dan mampu mewadahi aktivitas yang bisa membuat mereka nyaman setelah/sebelum beraktivitas. Selain itu, Taman Tebet sebagai bentuk ruang publik terbesar yang ada di kawasan Tebet perlu didorong untuk lebih mewadahi aktivitas masyarakatnya dengan lebih baik. Dari beragam potensi dan masalah tersebut, dirancanglah proyek yang berada dekat dengan Taman Tebet dan mampu mengakomodasi aktivitas masyarakat Tebet sebagai gerbang di antara tempat tinggal dan tempat kerja dengan program seperti pertokoan, tempat makan, sarana olahraga, fasilitas parkir dan tempat berkumpul dan bersantai untuk mewadahi aktivitas dan kebutuhan mereka.
\end{abstract}

Kata kunci: ruang ketiga; tebet; transit

\begin{abstract}
The life of Jakarta's people who are very dynamic in their routine sometimes makes them forget the importance of socializing and resting for a while. The need for a third place, in addition to home and workplace, could be a solution to provide space that is able to make people forget their main activities and relieve fatigue from their routine in order to have a better quality of life. Tebet as one of the densely populated residential areas in Jakarta certainly needs this third place so that its people can have a better quality of life. The existence of many kinds of public transportation in Tebet such as electric trains, Transjakarta buses and LRT (which are still in the development stage) makes the flow of the movement of people who are the users become very dynamic. The space between the house and the transportation points is needed as a third place that becomes a transit point and can accommodate activities that can make them comfortable after / before their routine. In addition, Tebet Park as the largest form of public space in the Tebet area needs to be encouraged to better accommodate the activities of its people. From the various potentials and problems, project designed close to Taman Tebet that able to accommodate the activities of the Tebet community as a gate between home and work place with programs such as shops, restaurants, sports facilities, parking facilities and a place to gather and relax to accommodate their activities and needs.
\end{abstract}

\section{Keywords: tebet; third place; transit}




\section{PENDAHULUAN}

Kehidupan masyarakat perkotaan yang serba cepat dan dinamis yang disebabkan oleh hiruk-pikuk rutinitas mereka kadang membuat mereka "lupa" untuk beristirahat dan bersantai sejenak yang kadang juga mampu membuat interaksi social mereka berkurang atau bahkan hilang. Rutinitas dari rumah ke tempat kerja begitu sibuk dilakukan terus-menerus, membuat kehidupan sehari-hari menjadi cenderung membosankan. Hal itulah yang kemudian dapat menurunkan kualitas hidup seseorang. Dibutuhkan tempat lain, selain rumah dan kantor, untuk seseorang dapat terbebas dari rutinitasnya dan dapat melakukan kegiatan yang bersifat menyenangkan dan menciptakan interaksi social yang baik di masyarakat sehingga memberi dampak positif bagi kehidupannya. Kebutuhan akan ruang ketiga atau Third Place ini dibutuhkan diantara kawasan permukiman dan perkantoran.

Kawasan Tebet sebagai salah satu kawasan permukiman di kota Jakarta khususnya Jakarta Selatan tentu juga membutuhkan hal tersebut. Jumlah usia produktif yang mencapai hampir $80 \%$ dari total jumlah penduduk di kawasan Tebet (Sensus, 2015) membuktikan bahwa banyak masyarakat Tebet yang masih disibukkan dengan pekerjaan dan rutinitasnya sehari-hari. Kebutuhan akan third place menjadi begitu penting dan dari situ peran arsitektur dapat bekerja dalam merancang ruang yang tepat dalam memenuhi kebutuhan masyarakat Tebet yang dapat mereka manfaatkan kapanpun disela rutinitas mereka sehingga kualitas hidup mereka dapat menjadi lebih baik.

\section{KAJIAN LITERATUR}

\section{Third Place}

Menurut buku The Great Good Place (Oldenburg, 1999) dijelaskan bahwa ada satu hal yang hilang dari kehidupan masyarakat modem yaitu keberadaan Third Place atau tempat ketiga. Ray Oldenburg menjelaskan bahwa Third Place adalah tempat untuk bersantai, pusat komunitas dan "home away from home" atau rumah yang jauh dari rumah, dimana seseorang merasa seperti di rumah yang menggambar tempat tersebut terasa hangat dan ramah. Third Place juga menjadi tempat dimana seseorang dapat berkumpul dengan orang-orang yang tidak mereka kenal untuk saling berinteraksi dan bersosialisasi dengan nyaman.

Dalam segi desain Third Place atau ruang ketiga ini digambarkan sebagai ruang bersantai yang menarik bagi masyarakat sekitar untuk mereka dapat bersosialisasi dengan orang yang tidak dikenal. Berkomunikasi atau berinteraksi di dalam ruang ketiga menjadi sebuah hal yang tidak akan mereka dapatkan di rumah maupun kantor. Dengan kondisi ini, masing-masing individu yang berada dan berkumpul di ruang ketiga ini dapat memperlihatkan masing-masing karakternya dengan jelas oleh karena adanya kebebasan bependapat dan saling bertukar pikiran yang terjadi disini. Dijelaskan juga bahwa ruang ketiga memiliki produk makanan dan minuman yang dapat dikonsumsi bersama-sama oleh siapa saja yang berkunjung, tidak ada agenda tertentu pada kegiatan ini, dan sifatnya informal. Pertemuan berkelompok yang terjadi disini tidak seperti rapat formal yang ada di kantor saat kita bekerja, melainkan adalah perternuan bersama secara santai untuk membahas hal apa saja yang ingin mereka bicarakan. Begitu juga dengan gaya berpakaian maupun model pakaian itu sendiri, tidak ada keharusan harus bergaya seperti apa ketika memasuki tempat ini.

Netral atau bersifat tidak memihak menjadi salah satu ciri utama dari Third Place yang baik setiap individu dibebaskan untuk menjalani kesehariannya disini, karena hal itu pula, pangkat, kondisi ekonomi, bahkan jabatan seseorang tidak terlihat disini. Di kebanyakan tempat lainnya, sangat terlihat perbedaan antara karyawan, pengunjung, dan pemilik, namun tidak pada sebuah ruang ketiga, mereka terlihat sama dan bahkan para karyawan dapat tetap bersosialisasi saat mereka sedang bekerja. Percakapan atau interaksi menjadi fokus utama di tempat ketiga, selain itu, minum, makan, musik, tarian dan hiburan lainnya juga dapat ditemui disini. Beberapa contoh interaksi yang digambarkan pada ruang ketiga seperti : membicarakan kehidupan mereka baik di kantor maupun dirumah, membicarakan apa yang sedang terjadi hari itu atau topik yang sedang hangat dibicarakan, atau sekedar berkenalan satu sama lain. 


\section{Arsitektur Komersial}

Arsitektur komersial merupakan arsitektur yang bangunan nya didirikan untuk mendapatkan keuntungan dari aktivitas komersial berupa kegiatan langsung jual, beli dan sewa pada bangunan tersebut dengan jangka waktu yang tertentu. Arsitektur harus mampu menunjukkan tiga kualitas, yaitu kegunaan-kekokohan-keindahan. Sisi estetika menjadi penting bagi arsitektur karena keindahan (dalam hal ini keindahan visual) adalah faktor pertama yang dipersepsi oleh individu, yang pada akhirnya menjadi penentu awal apakah sebuah bangunan mampu mengundang pengunjung atau tidak. Adapun beberapa kriteria agar bangunan komersial tersebut dapat mengundang pengunjung yang banyak antara lain:

a. Faktor pencitraan adalah nilai yang melekat pada suatu bangunan. Setiap bangunan komersial harus memiliki citra yang kuat dan bagus sebagai daya tarik terhadap calon konsumen.

b. Faktor ekonomi berkaitan langsung dengan aspek keuangan. Harga bangunan perlu disesuaikan terhadap target pasar dengan perawatan yang mudah dan hemat.

c. Faktor lokasi diukur dari strategis tidaknya posisi bangunan tersebut. Bangunan komersial sebaiknya dibuat di daerah-daerah yang mudah dicari, dilihat, dan dijangkau.

d. Faktor keamanan erat kaitannya dengan keselamatan para penghuni bangunan. Sebagai antisipasi juga perlu disediakan sarana dan prasarana pendukung keamanan bangunan.

e. Faktor investasi menyangkut kebutuhan jangka panjang konsumen. Faktor ini penting diperhatikan untuk mengantisipasi dinamika perubahan sosial.

f. Faktor kondisi wajib seirama dengan potensi dan karakter daerah pembangunan. Sebab faktor ini mampu menunjang kelancaran aktivitas komersial dari bangunan tersebut.

g. Faktor sosial budaya menarik minat masyarakat setempat untuk menerima keberadaan bangunan seutuhnya. Hal ini juga akan mendorong kelancaran bisnis dari bangunan komersial tersebut.

h. Faktor teknologi artinya bangunan komersial seyogyanya dilengkapi dengan teknologi terbaru. Hal ini bertujuan untuk mengoptimalkan manfaat bangunan tersebut secara efektif dan efisien.

i. Faktor kenyamanan menciptakan perasaan betah bagi konsumen selama memiliki bangunan tersebut. Hal-hal yang terkait dengan faktor ini yaitu penghawaan, pencahayaan, audio, dan sirkulasi.

\section{Transit Oriented Development (TOD)}

Konsep Transit Oriented Development merupakan restrukturisasi konsep pembanguann kota yang berfokus pada fasilitas transit, yang telah dikenal sebelumnya pada awal abad ke-20 yang berupa konsep pengembangan terpadu pada stasiun kereta api dan Bus Rapid Transit sebagai fasilitas transportasi massal untuk commuter di Amerika Serikat. Proyek tersebut yang menjadi dasar pembentukan teori Transit Oriented Development oleh Calthrope. Konsep Transit Oriented Development diterjemahkan oleh Petrus Calthrope pada tahun 1980-an. Transit Oriented Development didefinisikan sebagai konsep yang menggunakan pola ruang mixed-use (campuran) yang mendorong orang untuk tinggal berdekatan dengan layanan transit serta untuk mengurangi ketergantungan orang terhadap mengemudi (atau menjadi komuter). Konsep Transit Oriented Development di anggap sebagai salah satu konsep perancangan kota yang berkelanjutan untuk masyarakat. Konsep Transit Oriented Development dapat menjadi salah satu alternatif perancangan kota untuk pertumbuhan daerah. Perkembangan kota yang mengarah pada konsep Transit Oriented Development berpotensi untuk meningkatkan kualitas hidup masyarakat dan mengurangi biaya transportasi rumah tangga sedangkan untuk wilayah dengan pola ruang mixed-use dapat mengurangi sampak lingkungan dan memberikan alternatif untuk mengurangi kemacetan lalu lintas. 


\section{METODE}

Metode pengumpulan data yang dibutuhkan dalam perancangan menggunakan metode observasi dan wawancara secara lisan. Pengumpulan data dilakukan pada area sekitar tapak dan area Taman Tebet untuk mencari tahu kebutuhan masyarakat yang ada pada area tersebut dan kelebihan dan kekurangan yang ada dalam tapak.

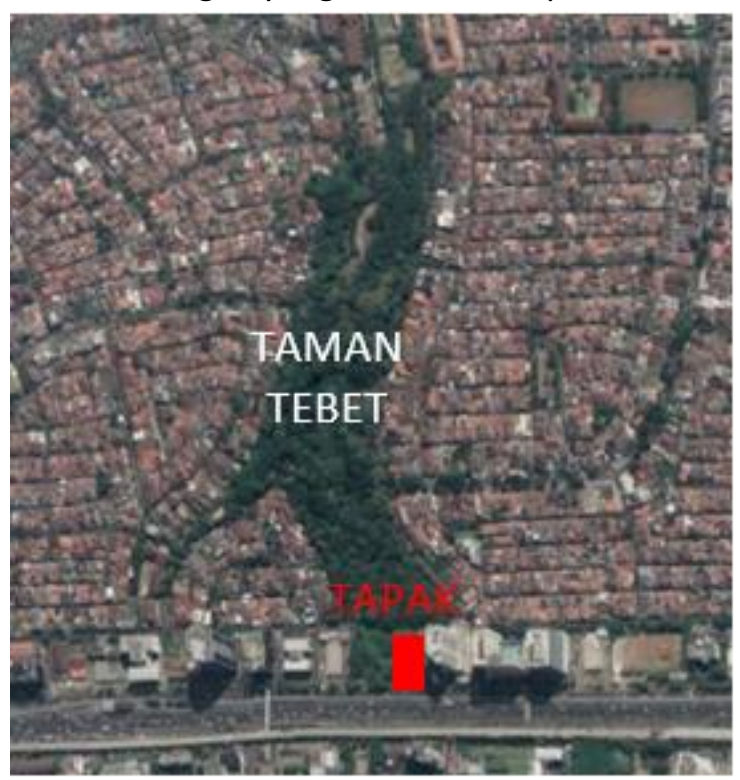

Gambar 1. Lokasi Pengumpulan Data Sumber : Dokumen Pribadi, 2019

Metode perancangan menggunakan metode Tipologi Ruang Kegiatan yang dijelaskan dalam buku Metode Perancangan (Gunawan Tjahjono, 2000). Metode Tipologi Ruang Kegiatan dilakukan dengan cara memahami kegiatan manusia yang paling mendasar. Dengan mempelajari kegiatan manusia secara baik, kegiatan tersebut menciptakan sebuah ruang. Dalam konteks kegiatan dalam bangunan third place, perancang perlu mencari kegiatan apa saja yang mungkin terjadi sehingga dari kegiatan tersebut dapat mengetahui kebutuhan ruang, terutama yang mampu menciptakan interaksi social antar pengunjung serta memberi ruang untuk beristirahat dari rutinitas. Selain itu perancang perlu memahami ergonomic yang dibutuhkan dalam menentukan ruang agar luasan ruang dapat sesuai dengan kapasitas yang diperkirakan sehingga ruang menjadi nyaman untuk digunakan. Contoh hal-hal yang perlu diperhatikan meliputi :

a. Sirkulasi kendaraan dari luar maupun dalam bangunan harus jelas dan mudah dipahami.

b. People Movement atau alur sirkulasi manusia dari dan menuju bangunan, dalam hal ini perlu diperhatikan juga bagi pedestrian yang berasal dari luar tapak.

c. Memperhatikan ergonomi ruang serta perabot yang dipakai sehingga besaran ruang dapat dirancang senyaman mungkin bagi aktivitas yang terjadi di bangunan.

d. Fungsi ruang harus memperhatikan keadaan atau faktor-faktor yang ada di lingkungan sekitar tapak, untuk menciptakan program yang sesuai.

Dengan memperhatikan hal-hal tersebut, akan lebih mudah untuk mencari tahu kegiatankegiatan apa saja yang dibutuhkan masyarakat dan dari situ dapat menghasilkan program ruang yang sesuai untuk kawasan Tebet.

\section{DISKUSI DAN HASIL}

Bangunan dirancang dengan konsep yang dipengaruhi oleh lingkungan sekitar yaitu aktivitas di Tanan Tebet dan alur pejalan kaki yang menggunakan transportasi publik (KRL, 
Busway, dII). Dari situlah didapatkan program utama yang mewadahi aktivitas komersil, olahraga, fasilitas parkir kendaraan bermotor serta sebagai ruang publik yang terbuka bagi siapa saja. Bangunan ini memiliki 16 lantai ditambah dengan 3 lantai basemen untuk memenuhi kebutuhan parkir. Bangunan dirancang vertikal untuk memaksimalkan penggunaan program di lahan yang tidak terlalu besar $\left(4.030 \mathrm{~m}^{2}\right)$. Berikut beberapa gambar hasil perancangan.

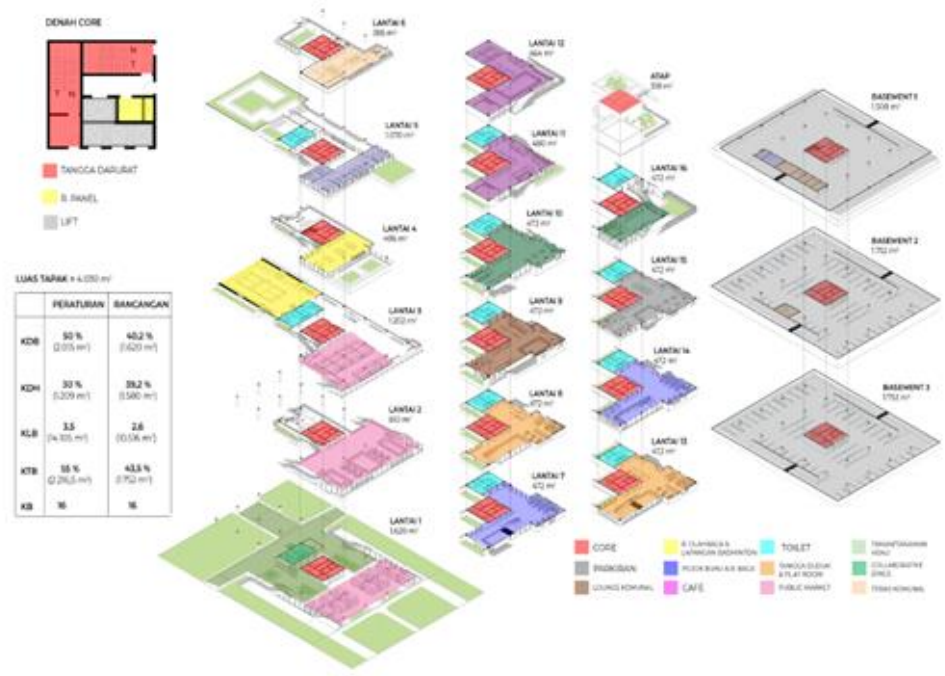

Gambar 2. Program \& Luas Bangunan Sumber : Dokumen Pribadi, 2019
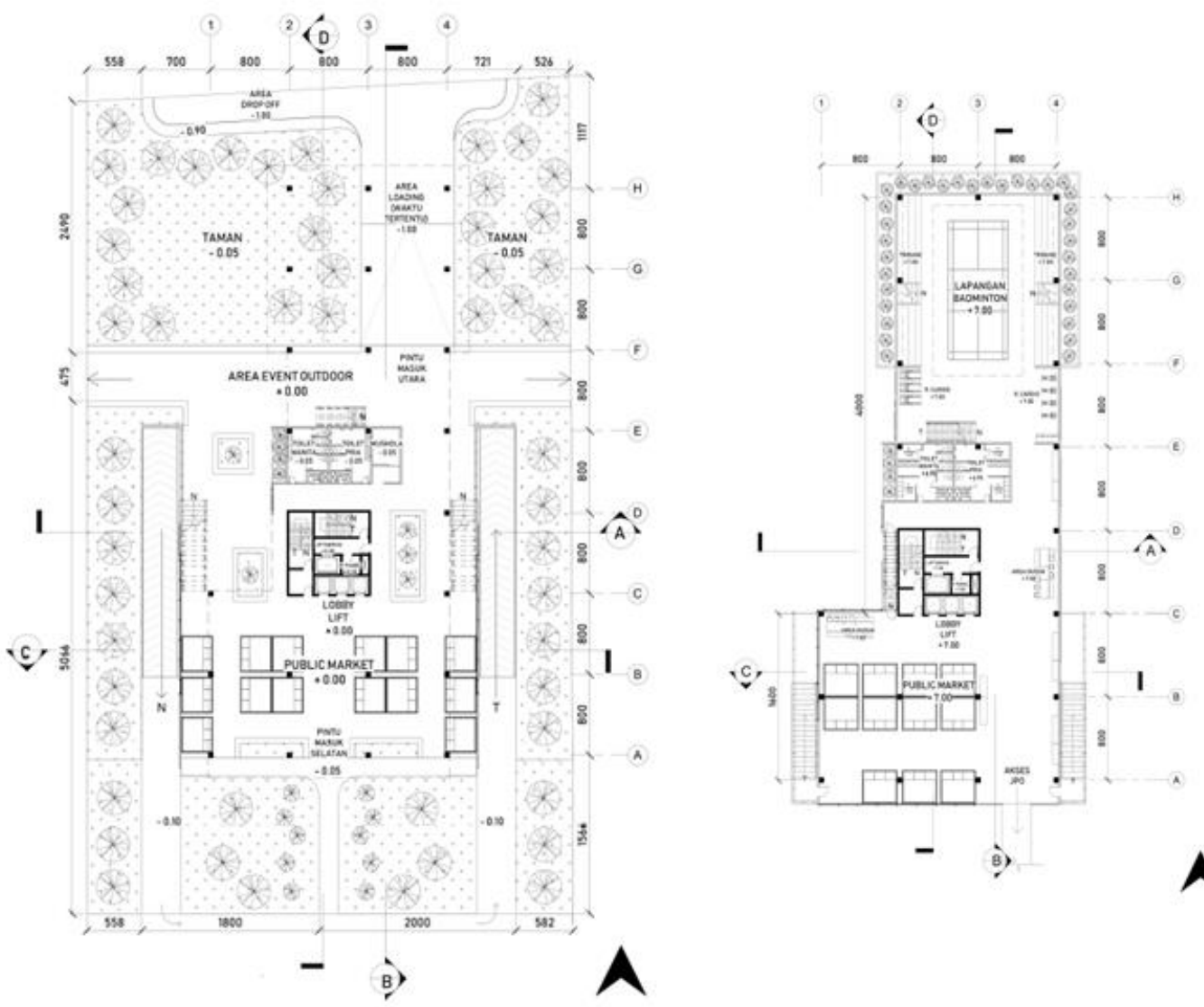

Gambar 3. Denah Lantai 1 (kiri) \& Lantai 3 (kanan) yang merupakan bagian podium bangunan Sumber: Dokumen Pribadi, 2019 


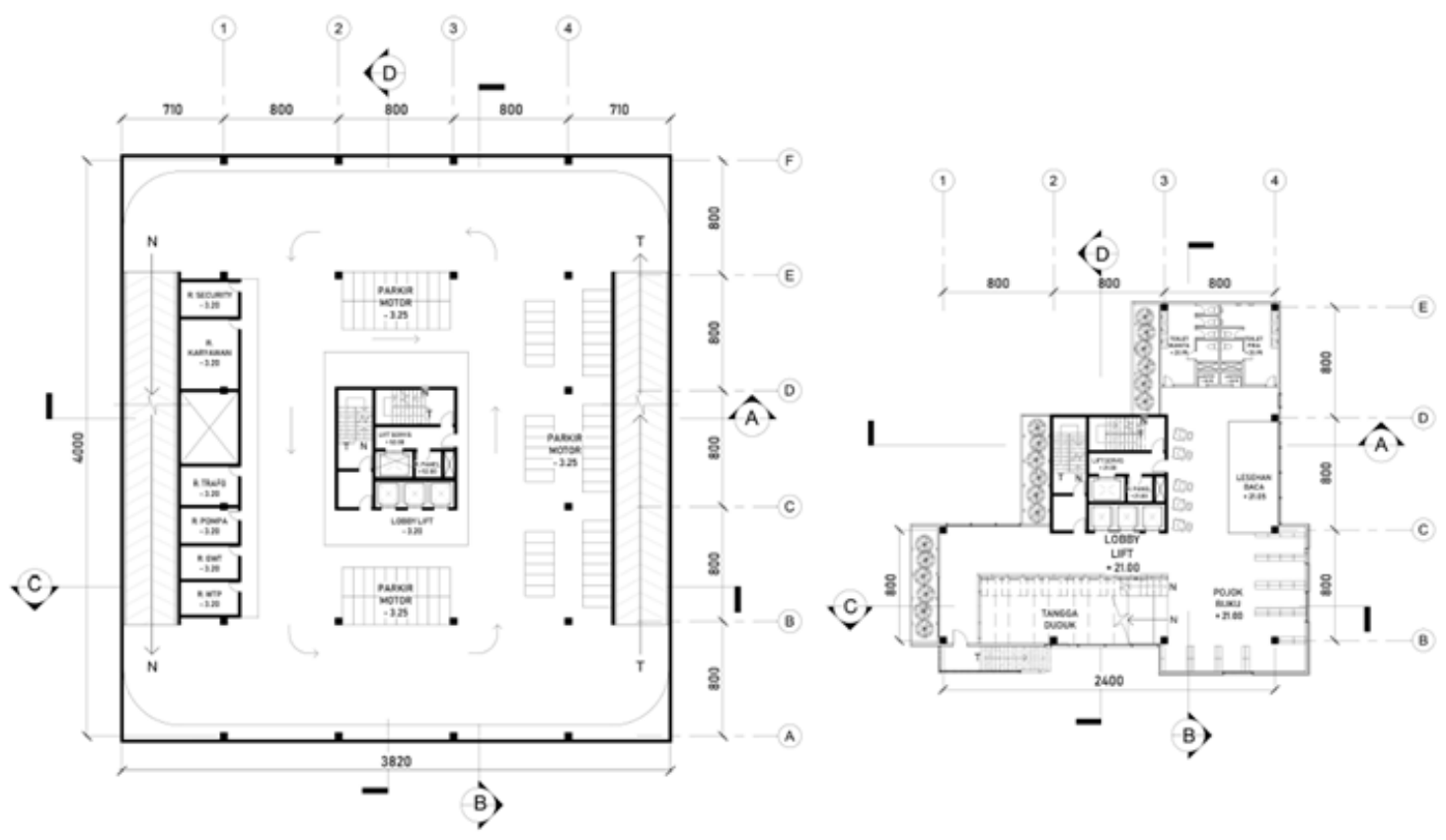

Gambar 4. Denah Basement 1 (kiri) \& Lantai 7 (kanan) sebagai masing-masing fasilitas parkir dan tempat berkumpul

Sumber: Dokumen Pribadi, 2019
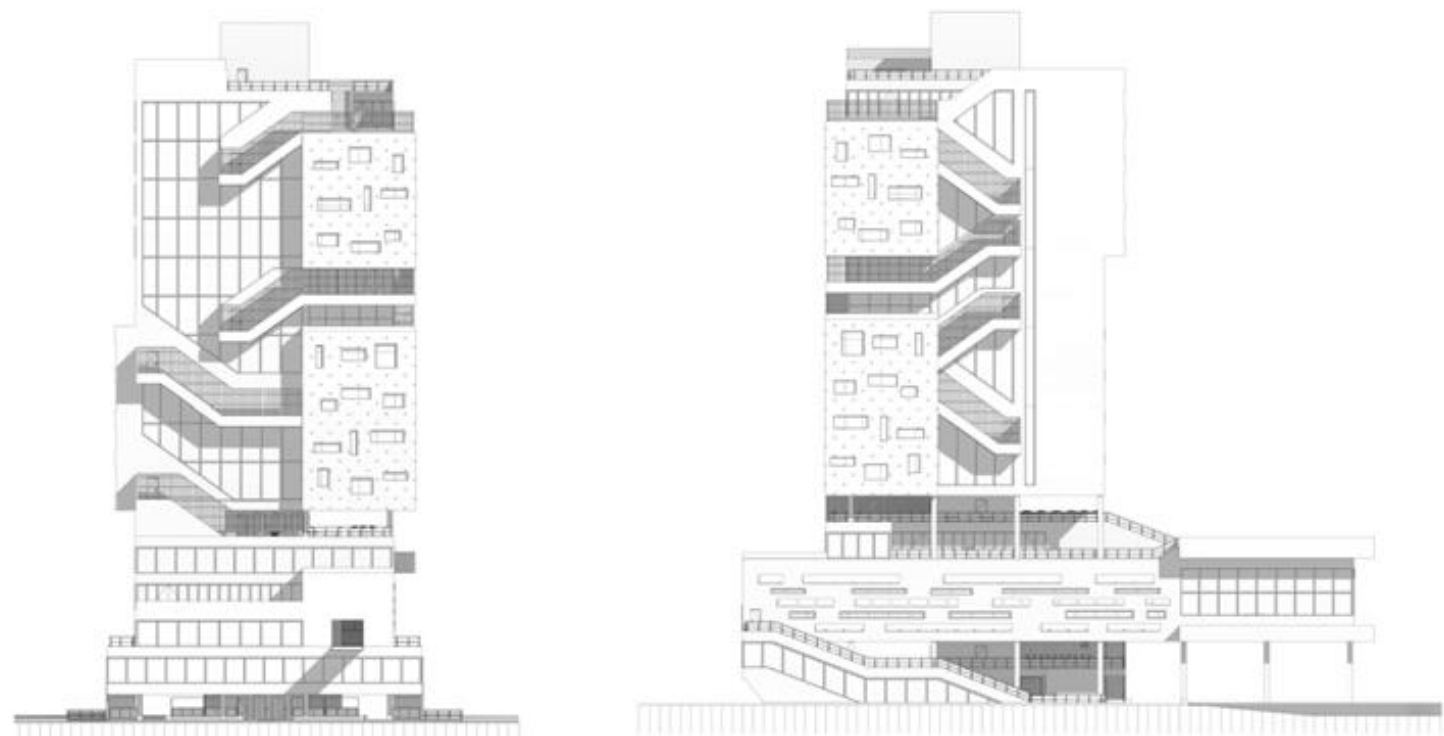

Gambar 5. Tampak Depan (kiri) \& Tampak Kanan (kanan) bangunan

Sumber: Dokumen Pribadi, 2019 

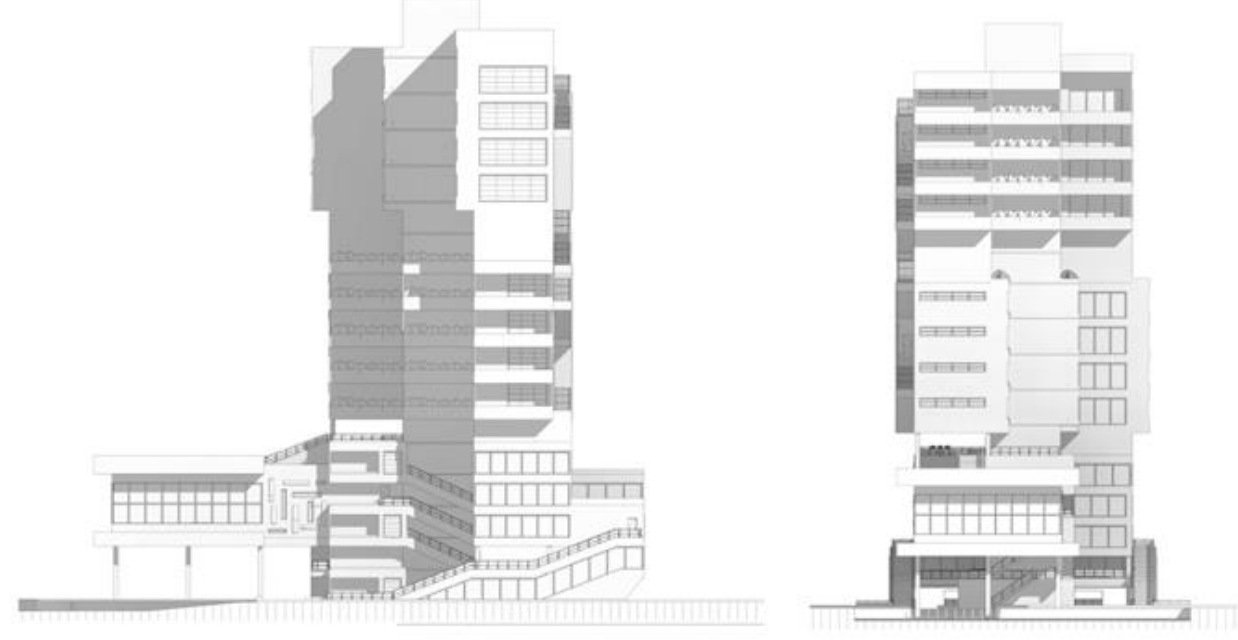

Gambar 6. Tampak Kiri (kiri) \& Tampak Belakang (kanan) bangunan Sumber: Dokumen Pribadi, 2019

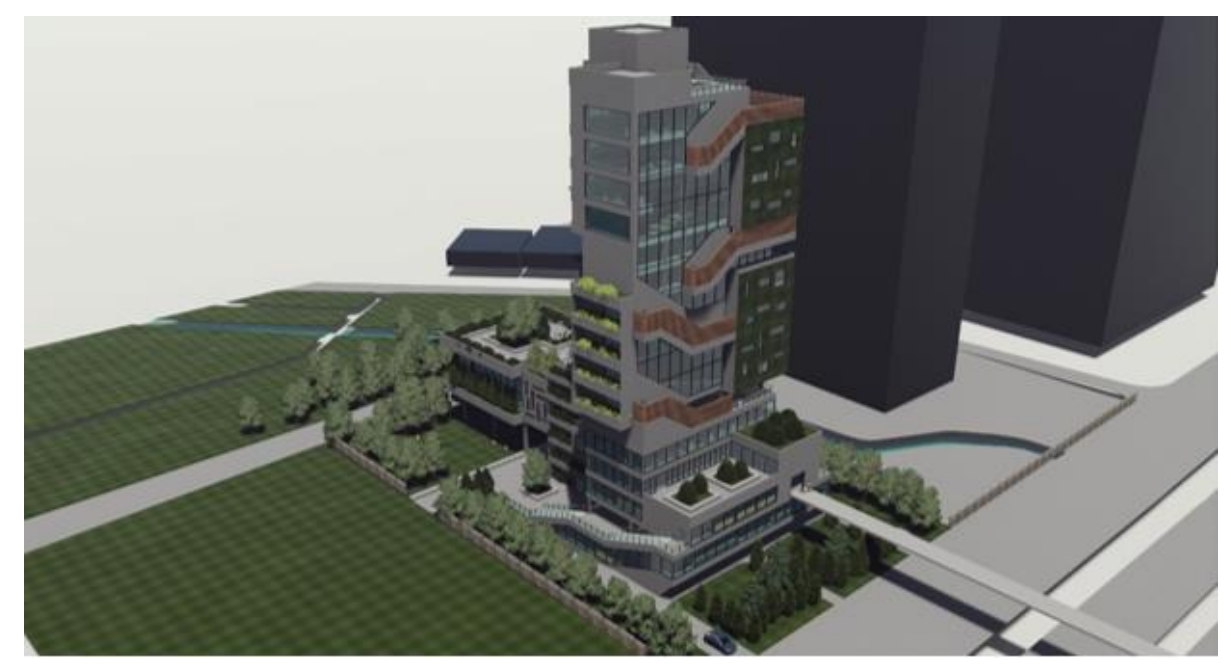

Gambar 7. Perspektif Eksterior Bangunan Sumber: Dokumen Pribadi, 2019

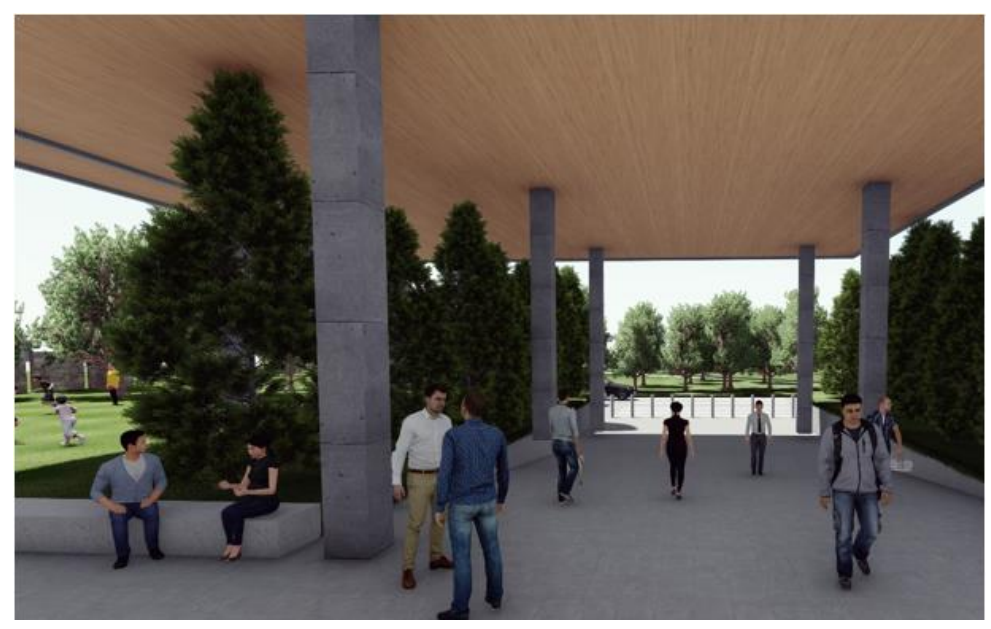

Gambar 8. Perspektif Interior Bangunan

Sumber: Dokumen Pribadi, 2019 


\section{KESIMPULAN DAN SARAN}

Proyek ini dirancang agar mampu menjadi Third Place bagi masyarakat Tebet yang pada akhirnya memberi ruang publik dimana masyarakat dapat berinteraksi sosial dengan sekitar dan menjadi tempat istirahat sejenak dari rutinitasnya. Lokasi bangunan yang dipilih diantara lokasi permukiman (First Place) dan tempat kerja (Second Place) yang diwakili dengan titik-titik transportasi publik seperti LRT, KRL dan bus TransJakarta diharapkan mampu membuat bangunan tersebut dapat diakses dengan mudah dan dimanfaatkan dengan sebaik-baiknya oleh masyarakat Tebet untuk mewadahi aktivitas yang dibutuhkan mereka. Program yang dirancang seperti pertokoan, tempat makan, sarana olaharga, fasilitas parkir, dan tempat berkumpul dan bersantai dibuat utuk mewadahi kegiatan masyarakatnya untuk dapat meningkatkan kualitas hidup masyarakat khususnya daerah Tebet.

Dalam perancangan Arsitektur, terutama dalam hal ini yang berhubungan dengan tema third place, diperlukan untuk melakukan penelitian dan observasi yang mendalam terhadap tapak dan lingkungan sekitar lokasi perancangan serta kondisi masyarakat sekitar tapak. Dari situ akan menjadi lebih mudah untuk dapat merancang program yang tepat dan memang dibutuhkan bagi masyarakat sekitar sebagai wadah third place mereka sehingga bangunan yang dirancang dapat memberi dampak positif dan meningkatkan kualitas hidup dan menunjang aktivitas masyarakatnya dengan lebih baik.

\section{REFERENSI}

Calthorpe, P. (1993). The Next American Metropolis: Ecology, community, and the American Dream. New York: Princeton Architectural Press

Fauzi, M. (2018). Penerapan konsep Transit Oriented Development (TOD) sebagai solusi masalah transportasi di DKI jakarta. Politeknik Bandung

Indranilla, P. (2012). Affordance pada ruang publik. Universitas Indonesia

Langdon, P. (2017). Within Walking Distance. Washington: Island Press

Oldenburg, R. (1999). The Great Good Place. Boston: Da Capo Press

Safitri, D. (2017). Prinsip desain neo futuristik pada bangunan komersial karya Eero Saarinen. Universitas Medan Area

Tjahjono, G. (2000). Metode Perancangan: Suatu Pengantar untuk Arsitek dan Perancang. Jakarta: Universitas Indonesia

Widyasrini, M. (2011). Ruang peristiwa pada koridor distro Tebet. Universitas Indonesia 